\title{
Status of Mock-up and Integration for Ultrasonic Deformation Sensor for TREAT Experiments
}

Joshua Daw, Anthony Crawford, Richard Skifton, Lance Hone-INL Andrew Casella, Richard Jacob, Robert Montgomery-PNNL March 2019

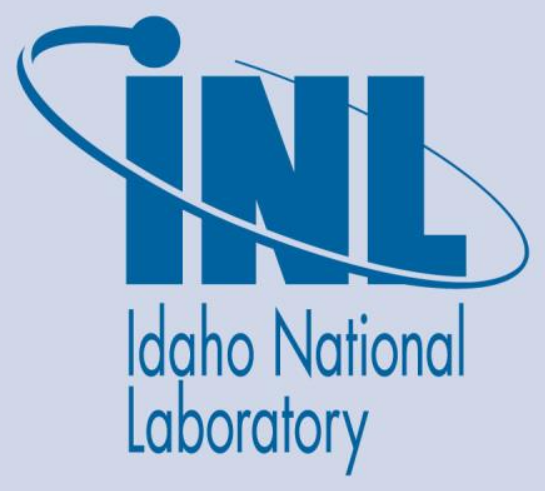

The INL is a U.S. Department of Energy National Laboratory operated by Battelle Energy Alliance 


\section{DISCLAIMER}

This information was prepared as an account of work sponsored by an agency of the U.S. Government. Neither the U.S. Government nor any agency thereof, nor any of their employees, makes any warranty, expressed or implied, or assumes any legal liability or responsibility for the accuracy, completeness, or usefulness, of any information, apparatus, product, or process disclosed, or represents that its use would not infringe privately owned rights. References herein to any specific commercial product, process, or service by trade name, trade mark, manufacturer, or otherwise, does not necessarily constitute or imply its endorsement, recommendation, or favoring by the U.S. Government or any agency thereof. The views and opinions of authors expressed herein do not necessarily state or reflect those of the U.S. Government or any agency thereof. 


\section{Status of Mock-up and Integration for Ultrasonic Deformation Sensor for TREAT Experiments}

Joshua Daw, Anthony Crawford, Richard Skifton, Lance Hone-INL Andrew Casella, Richard Jacob, Robert Montgomery-PNNL

March 2019

Idaho National Laboratory

Pacific Northwest National Laboratory

Idaho Falls, Idaho 83415

http://www.inl.gov

Prepared for the

U.S. Department of Energy

Office of

Under DOE Idaho Operations Office

Contract DE-AC07-05ID14517 


\title{
Status of Mock-up and Integration for Ultrasonic Deformation Sensor for TREAT Experiments
}

\author{
INL/EXT-19-53110 \\ Revision 0 \\ March 2019
}

Approved by:

Name

Date

Title [optional]

Name

Date

Title [optional]

Name

Title [optional]

Date

Name

Date

Title [optional] 


\section{SUMMARY}

Fuel deformation (both axial and radial) information provides insights into fuel performance and failure limits. Traditionally, fuel deformation has been quantified using post-irradiation examinations due to the lack of an appropriate sensor for monitoring deformation in situ. Recent developments in sensor and instrumentation design have led to the use of linear variable differential transformers (LVDT) for monitoring axial strain in fuel during irradiation. Size and operational constraints limit the use of LVDT sensors for radial deformation monitoring, and alternatives are needed.

One possible alternative to LVDT sensors is an ultrasonic sensor. Ultrasonic sensors monitor the interaction of high-frequency stress waves with the test object. The resulting response may be analyzed to determine the properties of the material, including stress, strain, microstructure, presence of defects, and the elastic constants. While ultrasonic measurements have been successfully applied for monitoring strain in a number of applications, their use for in-core measurements has been limited. Largely, the limitations are due to the challenges associated with designing sensors that can operate under typical in-core conditions.

This report documents progress to date toward planning, construction, and testing of a mock-up test capsule/facility to be used for in-lab testing of ultrasonic displacement sensor designs and toward integration of the sensor into prototypic TREAT experiment designs. 


\section{CONTENTS}

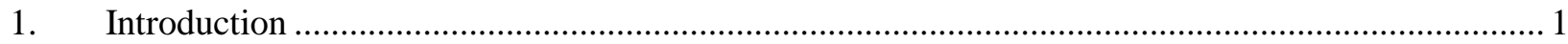

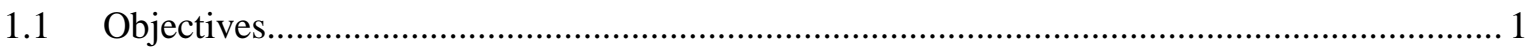

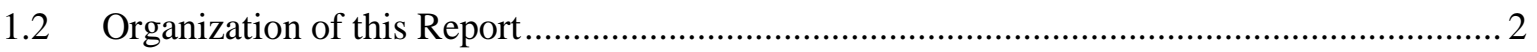

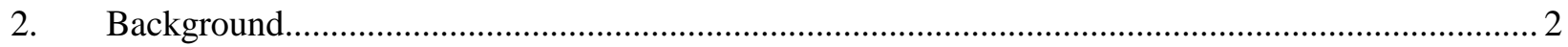

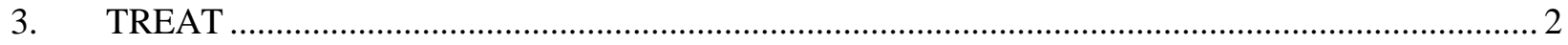

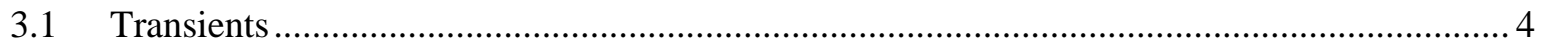

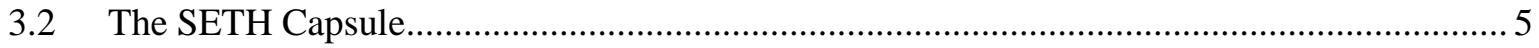

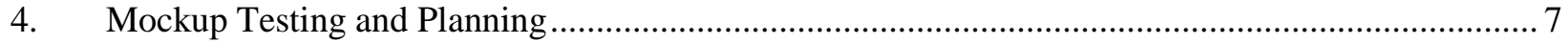

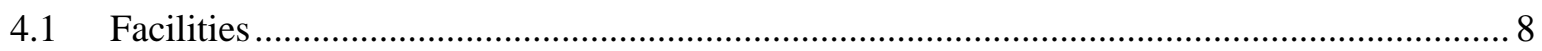

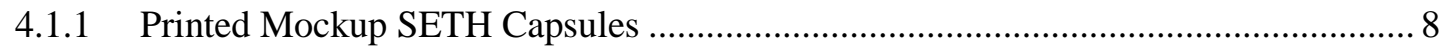

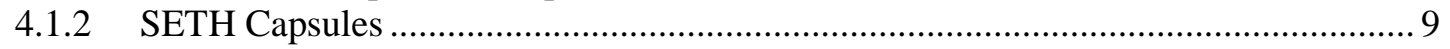

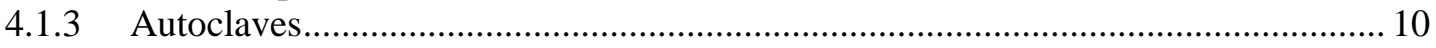

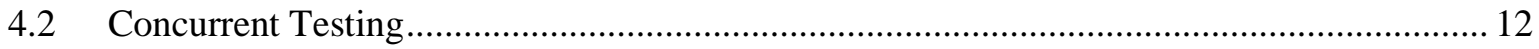

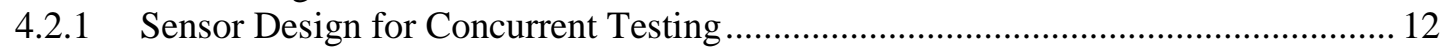

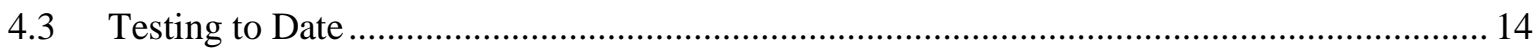

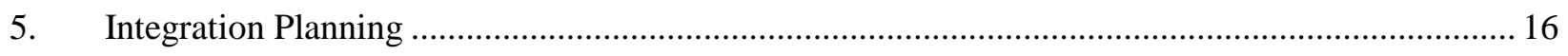

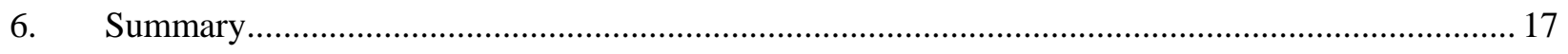

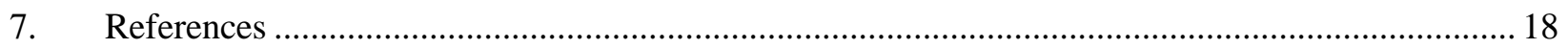




\section{FIGURES}

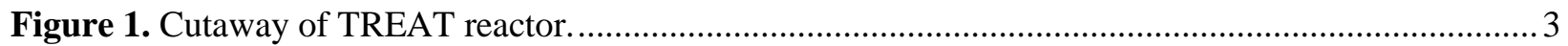

Figure 2. TREAT reactor central test position. ................................................................................ 4

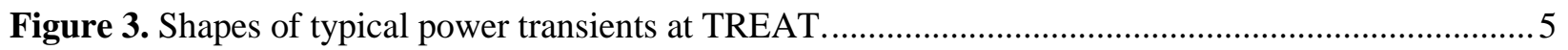

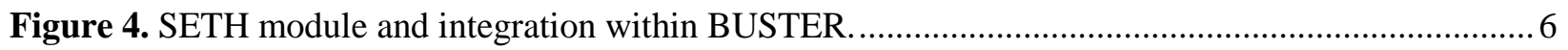

Figure 5. SETH capsule internal sensor supports and fuel pin surrogate............................................. 7

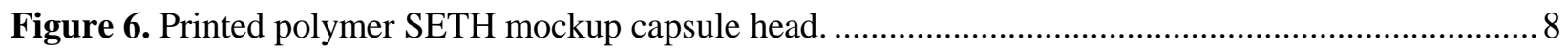

Figure 7. Modified SETH capsule head showing integration of Conax fittings. ..................................... 9

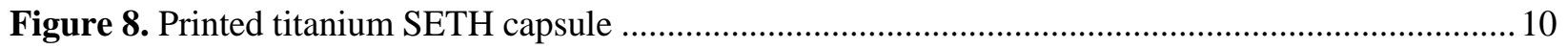

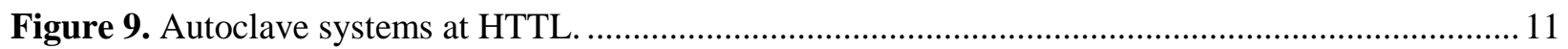

Figure 10. Installation of instrument test rods in TREAT cooling channels......................................... 12

Figure 11. Simplified sensor design for concurrent testing. ............................................................... 13

Figure 12. Plan view of reactor building showing locations of ex-core features.................................... 14

Figure 13. SETH capsule cap showing thermocouples and optical pyrometers installed on hanger structure. 


\section{ACRONYMS}

BUSTER

DAQ

DIC

DOE-NE

LVDT

LWR

MARCH

NDE

NEET-ASI

PWR

PZT

SETH

TREAT
Broad Use Specimen Transient Experiment Rig

Data Acquisition System

Digital Image Correlation

Department of Energy-Nuclear Energy

Linear Variable Differential Transformer

Light Water Reactor

Minimal Activation Retrievable Capsule Holder

Non-Destructive Examination

Nuclear Energy Enabling Technologies-Advanced Sensors and Instrumentation

Pressurized Water Reactor

Lead Zirconate Titanate

Separate Effects Test Holder

Transient REActor Test Facility 


\title{
Status of Mock-up and Integration Planning for Ultrasonic Deformation Sensor for TREAT Experiments
}

\author{
1. Introduction
}

The TREAT facility was specifically designed to conduct transient reactor tests to simulate conditions ranging from mild upsets to severe reactor accidents. Transient irradiation of nuclear fuel samples is performed to identify fuel performance limitations. Of particular interest is testing conducted on preirradiated fuel samples to determine end-of-life performance limits that typically dominate fuel design. A significant challenge in these tests is the deployment of instrumentation for quantifying fuel condition (such as temperature, thermal conductivity, and mechanical condition) while minimizing any changes in these conditions due to the presence of the sensor itself.

A host of instrumentation was used during the operation of TREAT between 1959 and 1994 [1] to generate data necessary for fuel performance quantification. Much of the instrumentation capability from the previous TREAT operations will need to be resurrected, and a significant development, qualification, and integration effort may be necessary before some of these measurement technologies can be redeployed. The unique operating characteristics of TREAT (short bursts of high energy radiation) also challenge many sensors and instrumentation that may otherwise be deployed in-pile in test reactors. Ongoing research and development is addressing several instrumentation needs for TREAT experiments, with details of these advances documented elsewhere [1-3].

Among the key parameters of interest for monitoring during transient tests is the deformation of each component of the fuel pin. While linear variable differential transformer (LVDT) transducers are a potential solution, the sensitivity and response times of these sensors may be limited. The size of typical LVDTs and need for a push-rod connected to the sample make them intrusive and difficult to use in a constrained environment (such as the test capsules proposed for use in TREAT [3]). In addition, typical LVDT sensors are limited in their ability to provide data on radial deformation of the fuel pins.

An ultrasonic measurement approach could enable rapid, accurate measurements of deformation in axial and radial directions in fuel pins during TREAT irradiation tests. This is the focus of the work described in this report.

The overall objective of this work is to design an ultrasonic sensor capable of rapid, non-contact, in-situ measurements of dimensional changes in pre-irradiated fuel during re-irradiation. Specifically, the proposed sensor design will target:

- Reliable operation at elevated temperatures (between $\sim 300^{\circ} \mathrm{C}$ and $600^{\circ} \mathrm{C}$ )

- Design compatibility with proposed near-term TREAT irradiation capsule concept designs [3]

- Direct measurement of fuel dimensional changes, including fuel rod diameter

- High-speed measurements to enable rapid characterization of changes during a transient test.

\subsection{Objectives}

The overall objective of this work is to design an ultrasonic sensor capable of rapid in situ measurements of dimensional changes in pre-irradiated fuel during re-irradiation. This is the third report detailing the development of the ultrasonic displacement sensor. The first described the functional and operational requirements to be met by the final sensor [4]. The second detailed selection of candidate materials for the sensor construction [5]. This report describes the state of planning and testing for 
mockup facilities and sensor integration with respect to the SETH capsule, which was selected as the initial target for application of this sensor.

\subsection{Organization of this Report}

Section 2 of this report briefly discusses background information on ultrasonic measurements. A brief description of TREAT is given in Section 3, with the initially targeted SETH capsule discussed in Section 4. Sections 5 and 6 describe the status of mockup testing and integration planning respectively. The report is summarized in Section 7.

\section{Background}

Ultrasonic measurements of deformation can provide nondestructive measurements of dimensional changes rapidly (within tens to hundreds of microseconds). Further these methods are sensitive to both microstructural changes due to damage (from thermal, mechanical, and irradiation environments) and gross structural changes (such as swelling). As a result, ultrasonic methods have been applied to address needs in the nondestructive evaluation of structural components in nuclear power plants (including fuel cladding) during periodic pre-service and in-service inspection inspections.

Ultrasonic measurements have been successfully used for nondestructive materials characterization, including nondestructive evaluation (NDE) of degradation and damage [10], microstructure characterization [11], quantification and visualization of structural changes [12,13] and process control [14]. Ultrasonic NDE is a critical element of the nuclear power industry's in-service inspection program for maintaining the integrity of the pressure boundary [15], and is being actively investigated for postirradiation examination of fuels [16]. Ultrasonic measurements, typically performed at $10 \mathrm{MHz}$ or higher [6], performed post irradiation show that fuel microstructural parameters, such as porosity and grain size, can be correlated to ultrasonic velocity $[7,16]$.

Ultrasonic methods historically have seen limited applicability to environments with high temperatures and irradiation. Though some environmental factors (such as temperature) affect the measurement (sound speed, for instance), the limitation is primarily due to the probes themselves. Most commonly, lead-zirconate-titanate (PZT) is used as the piezoelectric sensor material for ultrasonic nondestructive measurements. PZT is limited in its applicability at elevated temperatures (approximately above $300^{\circ} \mathrm{C}$ ). However, recent tests (through DOE-NE's NEET-ASI program) have identified a number of alternatives that can operate at elevated temperatures (in excess of $400^{\circ} \mathrm{C}$ ) and can survive irradiation [8]. Certain grades of PZT have also been demonstrated for use in imaging under-sodium in sodium fast reactors [12]. A number of prior studies have also examined piezoelectric sensor material survivability using in-pile sensor tests in materials test reactors and in ultrasonic characterization of irradiated fuel specimens $[6,7,9,16]$. Recent advances in high-temperature ultrasonic sensor design has led to ultrasonic sensors that have demonstrated survivability at $550^{\circ} \mathrm{C}$ for several weeks, under thermal cycling [17].

\section{TREAT}

TREAT (cutaway view shown in Figure 1. Cutaway of TREAT reactor.Figure 1) was constructed in the late 1950's and, after extensive use, was placed in standby in 1994 [18]. TREAT was designed to evaluate reactor fuels and structural materials under conditions simulating various types of nuclear excursions and transient undercooling situations in a nuclear reactor. Fuel meltdowns, reactions between coolant and metals (structural, fuel, or cladding), interaction between overheated fuel and coolant, and the transient behavior of fuels for high temperature systems can be studied. TREAT is an air-cooled reactor driven by a core of graphite blocks having a small concentration of dispersed uranium oxide. Prismatic columns of these graphite-fuel blocks are hermetically encapsulated in zirconium alloy sheet metal cladding. Aluminum-sheathed graphite reflector blocks at top and bottom of each fuel column form a fuel assembly with $1.2 \mathrm{~m}$ of active core length. Along with control rod, experiment, and graphite reflector assemblies, these fuel assemblies are placed on a 19×19 gridplate with 361 available positions; creating a 
configurable core that can be adjusted to suit particular nuclear parameters or experimental objectives [19].

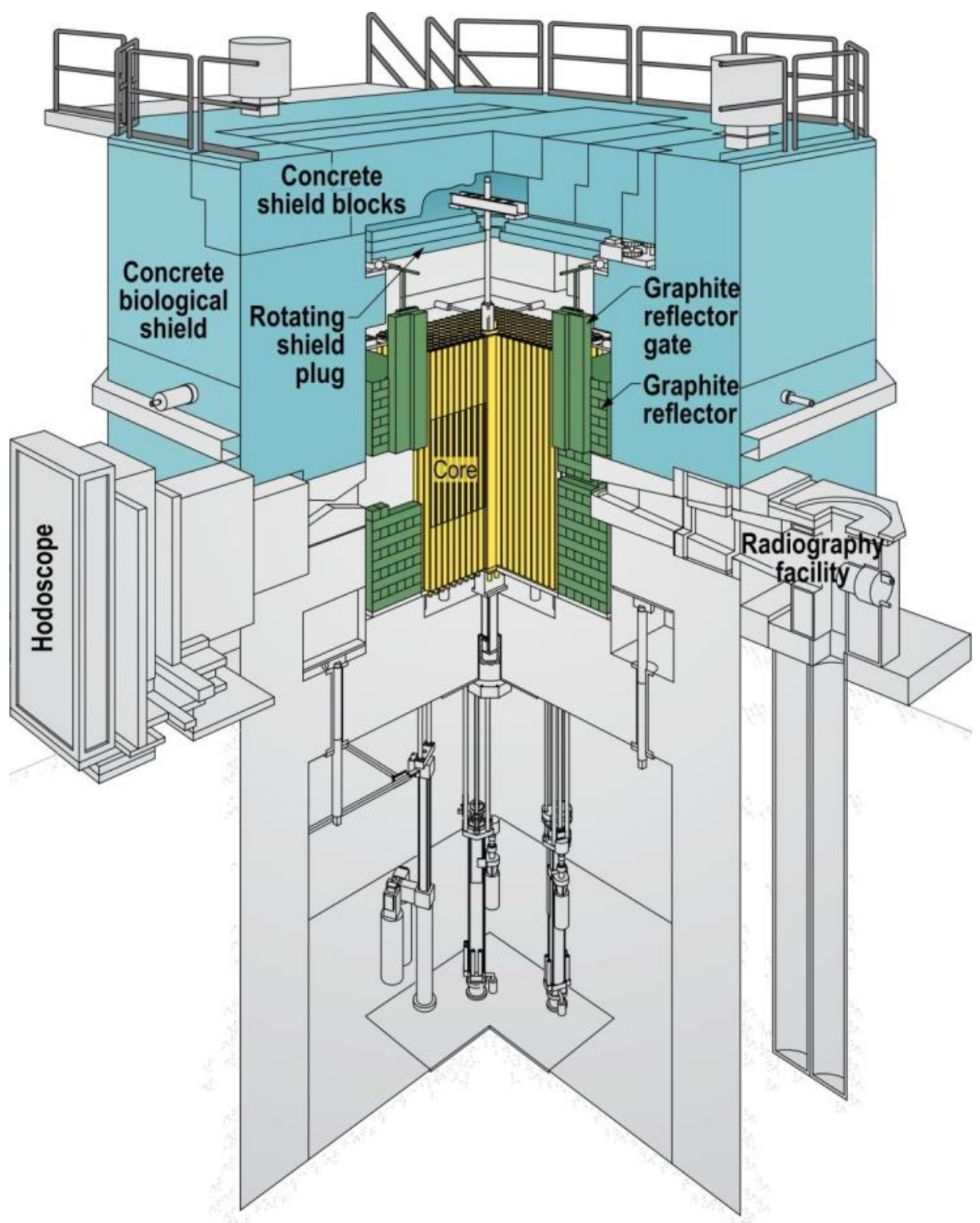

Figure 1. Cutaway of TREAT reactor.

A few fuel assemblies are typically removed from the central core positions to create a cavity for experiments (as shown in Figure 2). Experiment assemblies are typically removed from or placed into the core through a slot in the reactor's upper rotating shield plug, handled outside the reactor using shielded casks, and stowed below grade in storage holes when not in use. Four slots can be opened through the vertical concrete shield walls and permanent graphite reflector surrounding the above-grade core to provide various capabilities [20]. TREAT experiment rigs are, in essence, self-contained reactor vessels in which the neutrons are produced externally. Each rig (static capsule or loop) has its own double 
containment boundary and is simply lowered into the reactor test position, allowing for high throughput of experiments.

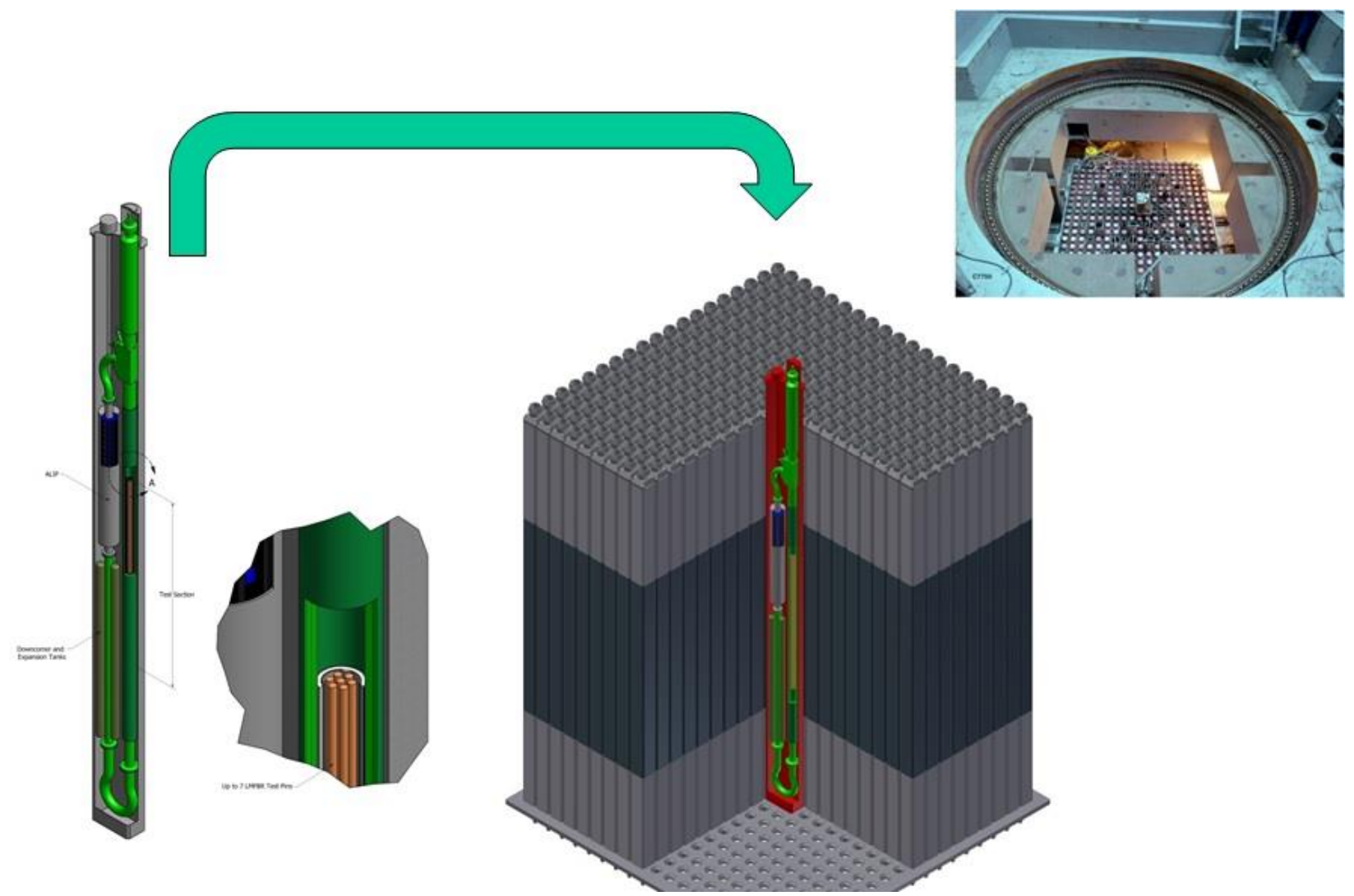

Figure 2. TREAT reactor central test position.

\subsection{Transients}

TREAT's transients can be shaped to vary over several orders of magnitude in terms of both reactor power and transient duration; the precise shape being practically governed simply by the core energy capacity (currently $2500 \mathrm{MJ}$ ). The shape of the TREAT is arbitrary, as long as the power/time profile is a function and the total integral energy is less than 2500 MJ. Figure 3 shows several simple transients which may be considered to encompass the extremes of TREAT transients in terms of power and duration [20]. 


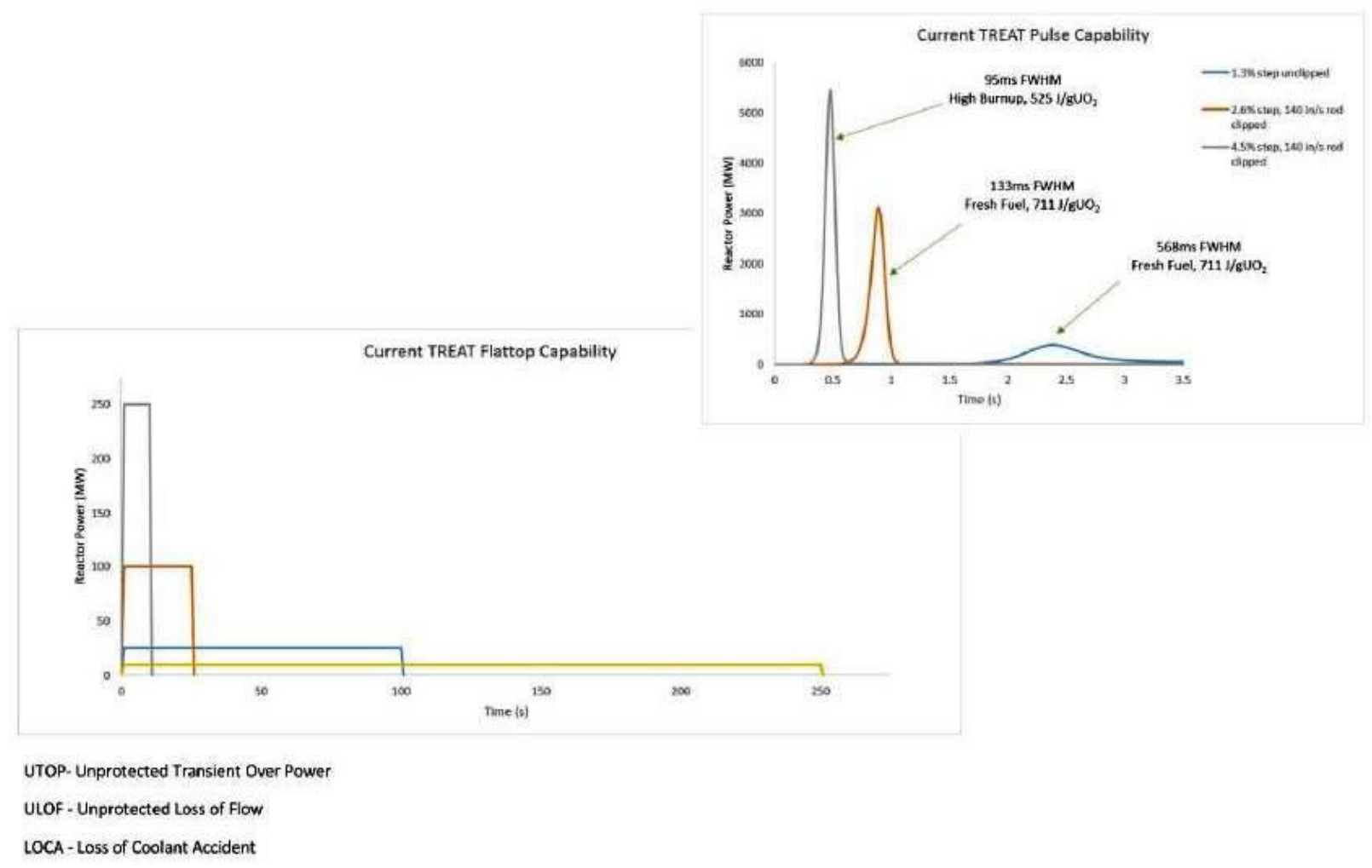

Figure 3. Shapes of typical power transients at TREAT.

\subsection{The SETH Capsule}

The Separate Effects Test Holder (SETH), shown in Figure 4 [20-22]. It contains sufficient volume for testing several forms of fuel samples, including LWR rodlets, MTR style plate fuels, etc., in nonprototypic sizes. The space available can also accommodate significant instrumentation, with feedthroughs using standard compression seals which can accommodate multiple 1-2 mm diameter MIMS cables. The SETH module does not currently include the capability for prototypic reactor coolant conditions (e.g. hot pressurized water, liquid sodium, etc.), but a room temperature, atmospheric pressure, water environment is planned. SETH has been identified as an ideal testbed for many applications including:

- Screening survivability tests. First round of testing for sensor in TREAT.

- Testing of sensor for sensitivity to reactor effects and signal noise characterization.

- Qualification testing with surrogate samples to demonstrate sensor performance.

Figure 5 shows a more detailed view of the SETH lid illustrating one planned test configuration. Aluminum structures are used for holding the central test specimen (a fuel rodlet or surrogate) as well as the instrumentation. These holders may be specially designed for different configurations and specimens, giving the SETH module tremendous flexibility for testing sensors in a variety of configurations. 

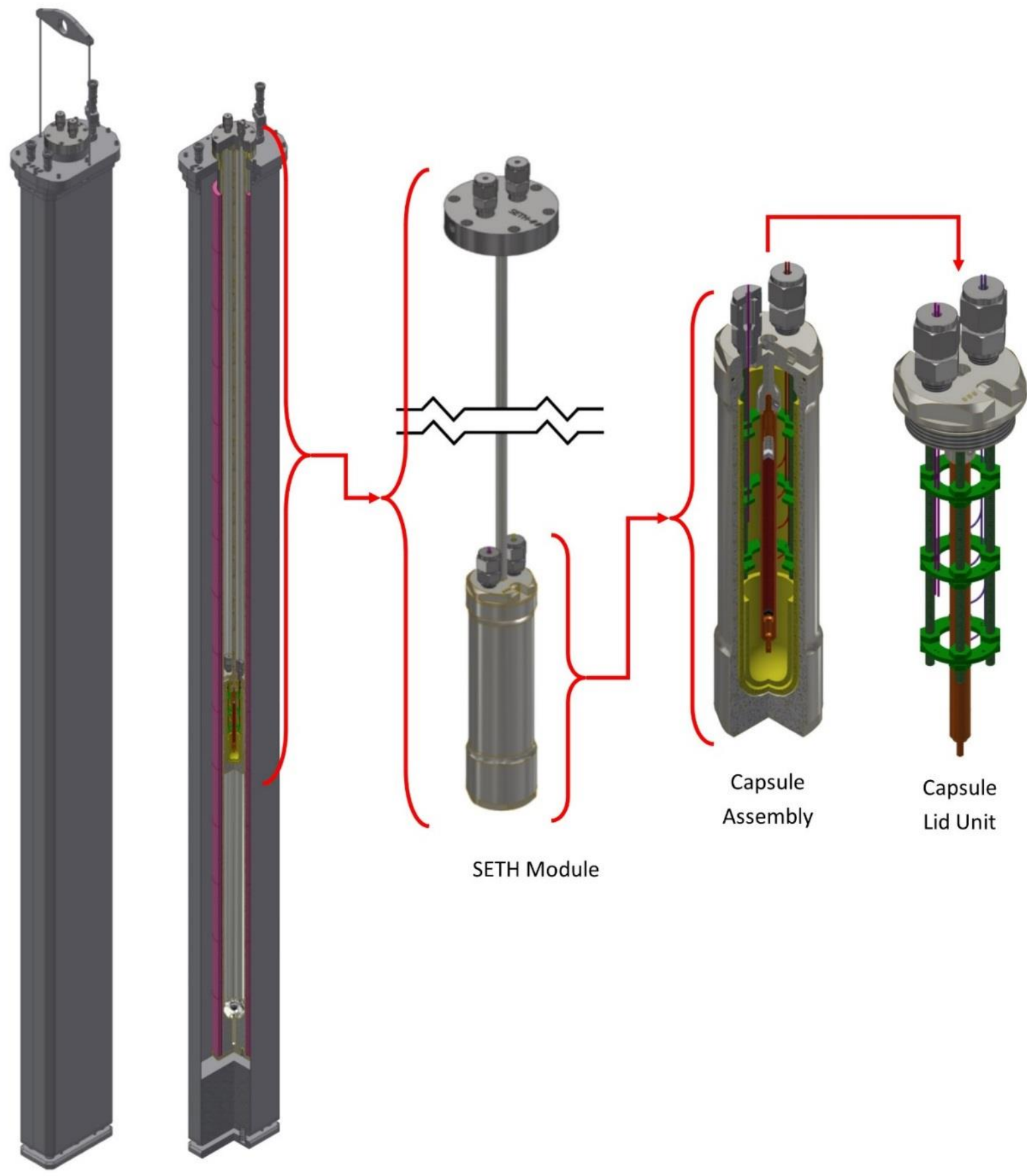

Irradiation Assembly

(SETH in BUSTER)

Figure 4. SETH module and integration within BUSTER. 


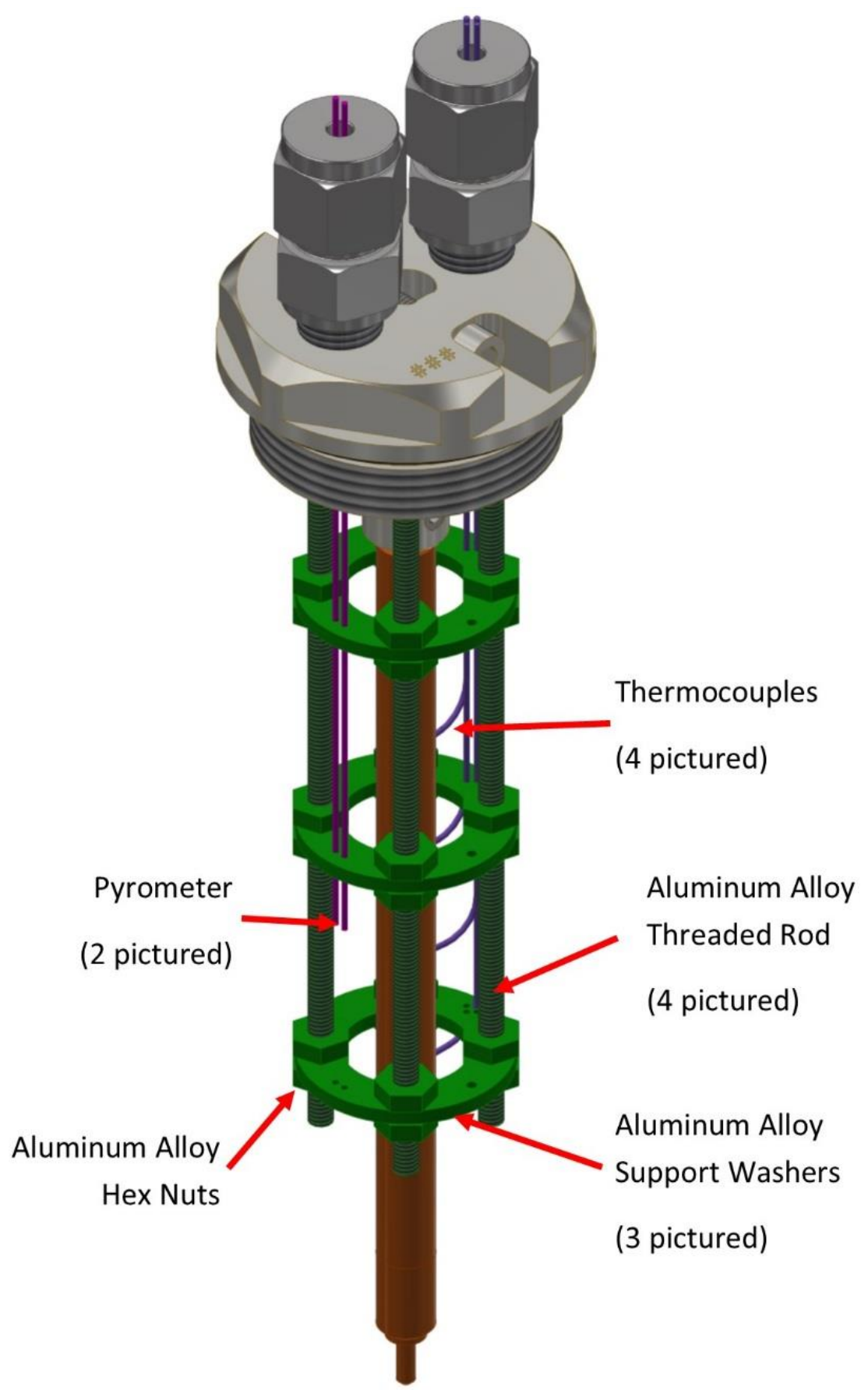

Figure 5. SETH capsule internal sensor supports and fuel pin surrogate.

\section{Mockup Testing and Planning}

This section describes progress to date in setting up mockup testing facilities and testing of prototypic sensors. 


\subsection{Facilities}

\subsubsection{Printed Mockup SETH Capsules}

Several 3-D printed polymer mockup SETH capsules have been procured. The mockups are identical in dimension to the production capsules. These mockups can be used for dimensioning of the sensor as well as limited air or water coupled testing of an internally installed sensor prototype. Primarily, these mockups are very useful for rapid design and testing of the internal sensor mounting hanger system. This system consists of a fuel rod hanger and a cage surrounding the fuel pin which accommodates installation of various sensors.

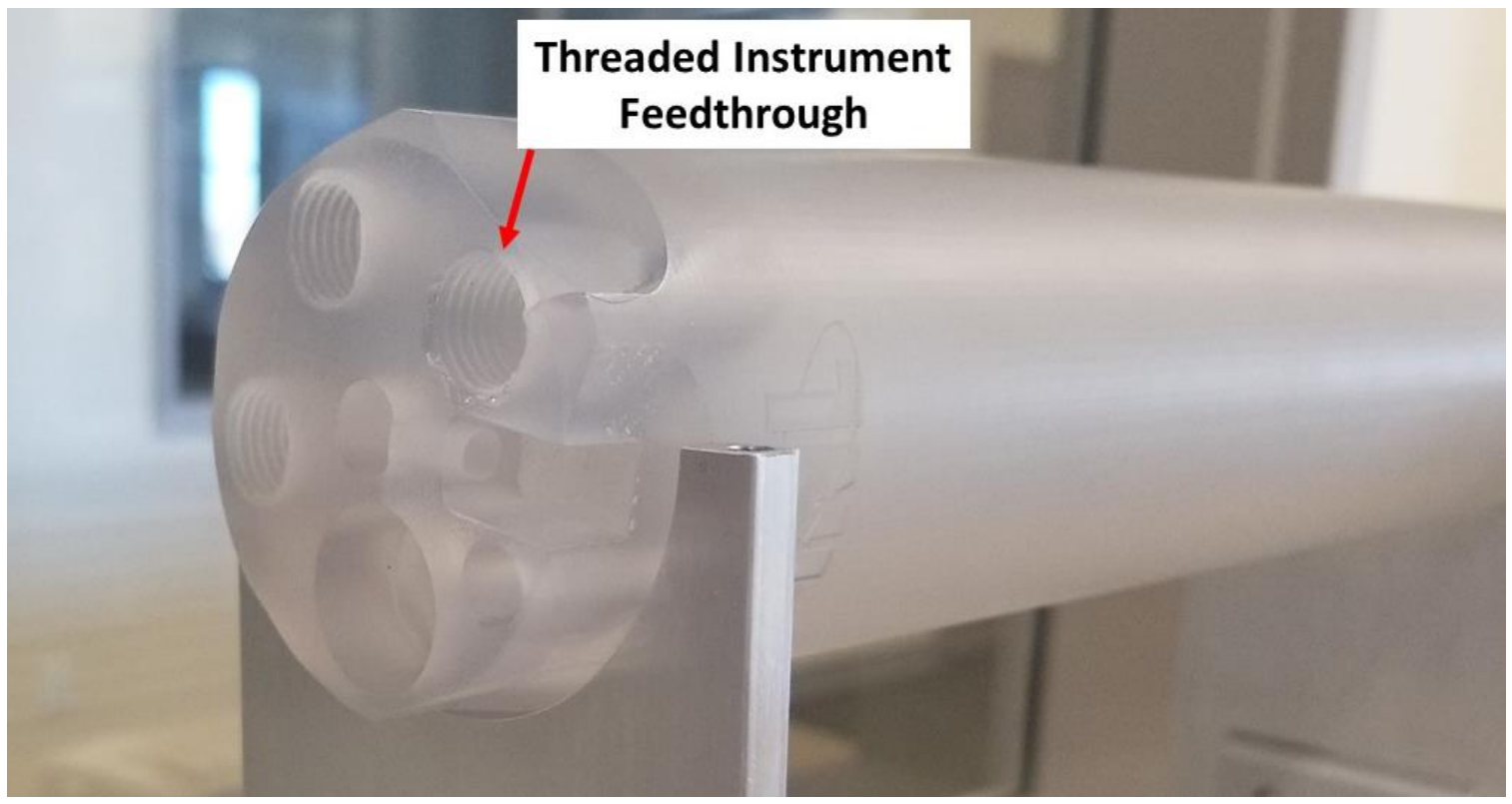

Figure 6. Printed polymer SETH mockup capsule head. 


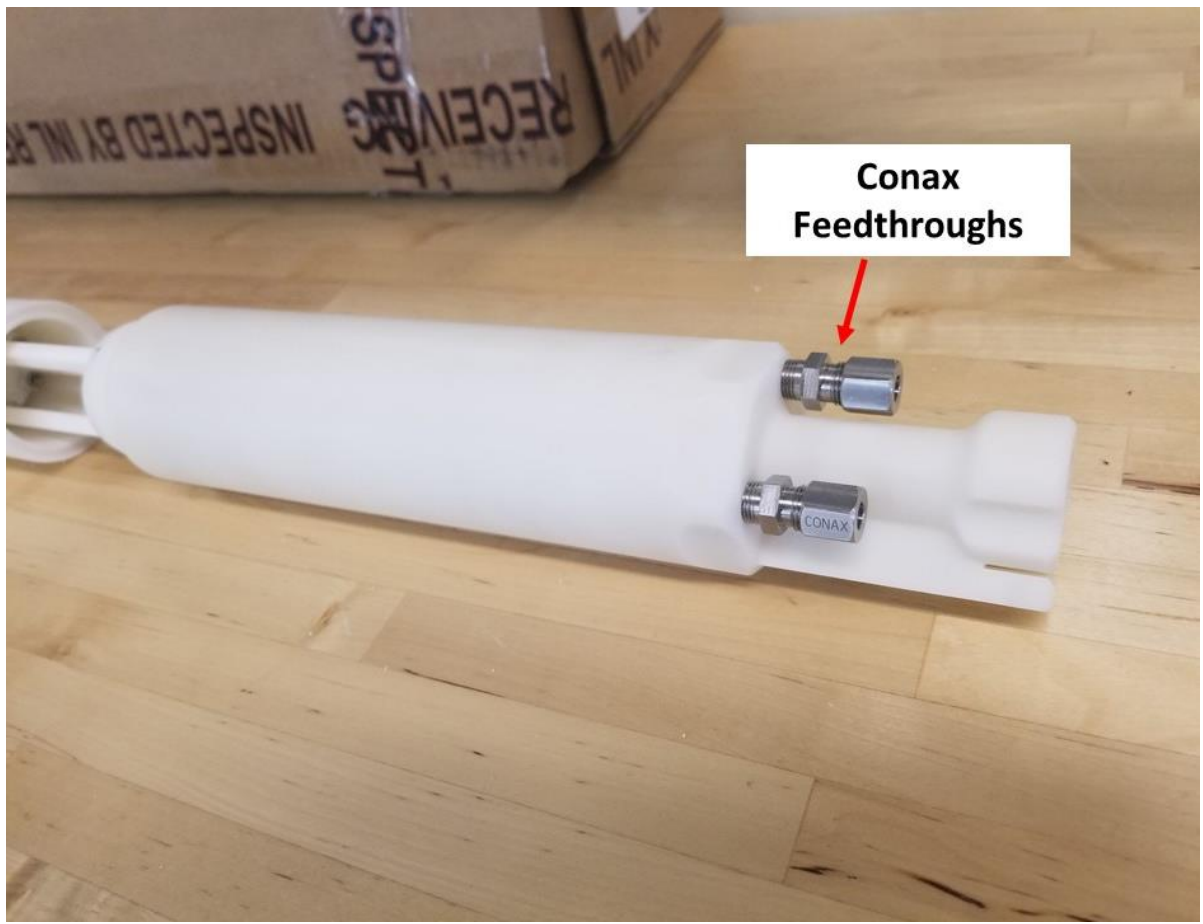

Figure 7. Modified SETH capsule head showing integration of Conax fittings.

\subsubsection{SETH Capsules}

As part of a recent order for the TREAT irradiation program, two SETH capsules have been purchased for use during mockup testing, but have not yet been received. The 3-D printed titanium capsules are identical to those used by the irradiation program and will be an ideal testbed for sensor development. By maintaining traceability of the capsules, it is possible that they might be used in future TREAT irradiations, possibly for in-core testing of the ultrasonic deformation sensor. 


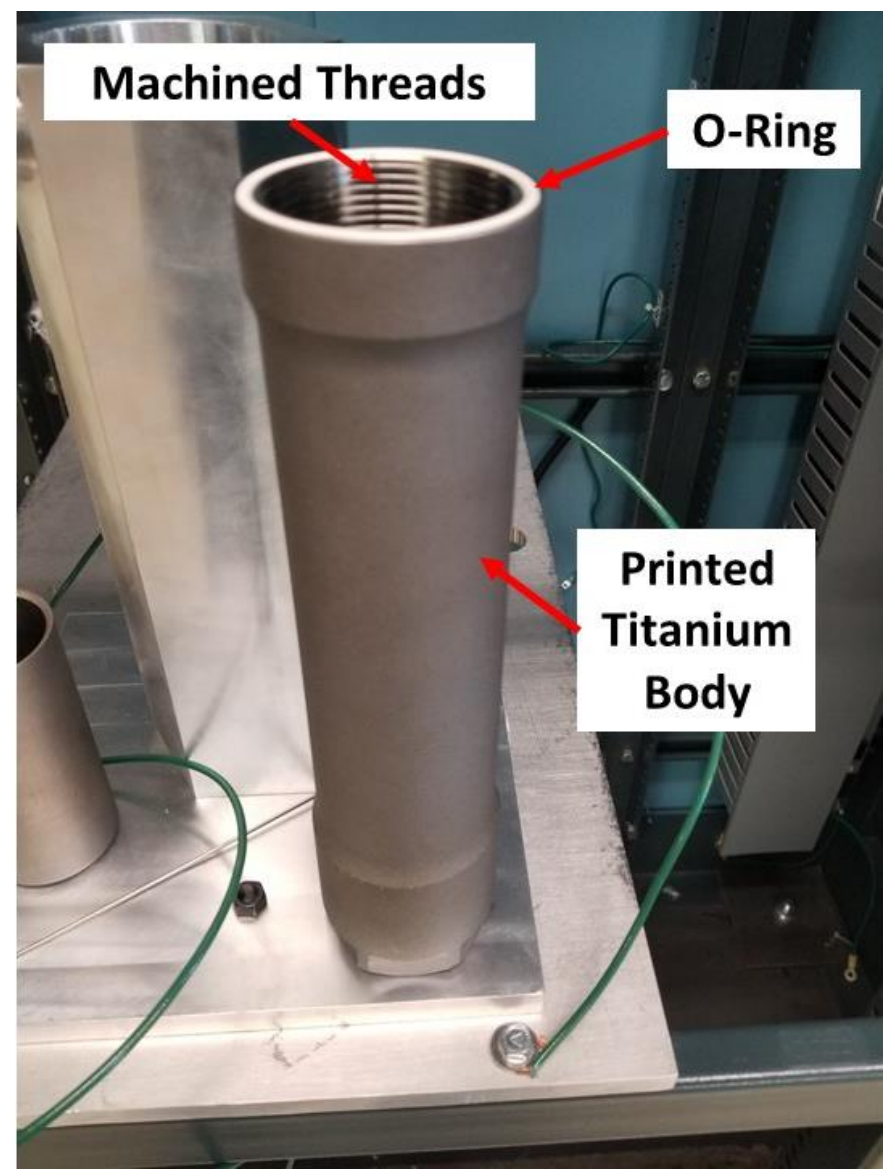

Figure 8. Printed titanium SETH capsule

\subsubsection{Autoclaves}

There are three autoclave systems which have been designed and built in the High Temperature Test Laboratory (HTTL) at the Idaho National Laboratory (INL) to provide test beds which can operate at Pressurized Water Reactor (PWR) prototypic pressures and temperatures to test advanced instrument concepts or other similar components. Autoclave \# 1 has a pressure vessel inside diameter of $12.7 \mathrm{~cm}$, a straight length of $15.96 \mathrm{~cm}$, with a volume of 2.0 liters. Autoclave \# 2 has a pressure vessel inside diameter of $12.7 \mathrm{~cm}$, a straight length of $27.86 \mathrm{~cm}$, with a volume of 3.785 liters. Autoclave \# 3 has a pressure vessel inside diameter of $15.11 \mathrm{~cm}$, a straight length of $60.97 \mathrm{~cm}$, with a volume of 12.11 liter (3.2 gal). Autoclaves \# 1 and \# 2 have a Maximum Allowable Working Pressure (MAWP) of $22.75 \mathrm{MPa}$ at $454{ }^{\circ} \mathrm{C}$. Autoclave \# 3 has a MAWP of $17.23 \mathrm{MPa}$ at $371{ }^{\circ} \mathrm{C}$. Water chemistry can be monitored and controlled on-line. The volumes of autoclaves \#2 and \#3 can accommodate a SETH capsule and leads for prototypic ultrasonic sensors, if a pressurized water environment is needed for testing. 


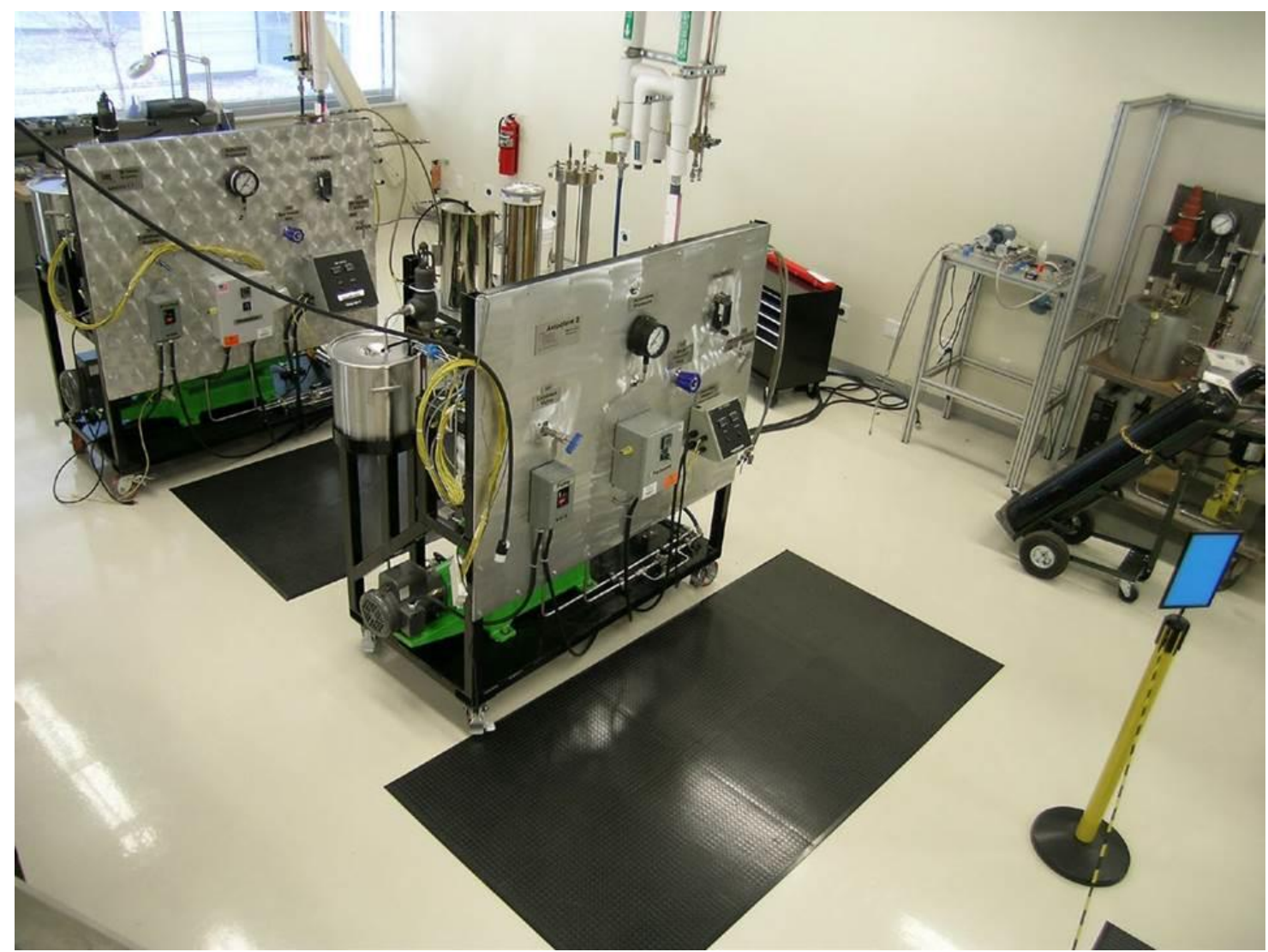

Figure 9. Autoclave systems at HTTL.

A digital image correlation (DIC) system to characterize deformation of pressurized tubes, which are then used to test ultrasonic measurement techniques. Samples have been created with different levels of permanent deformation (target 5\%,10\%, and 15\%).
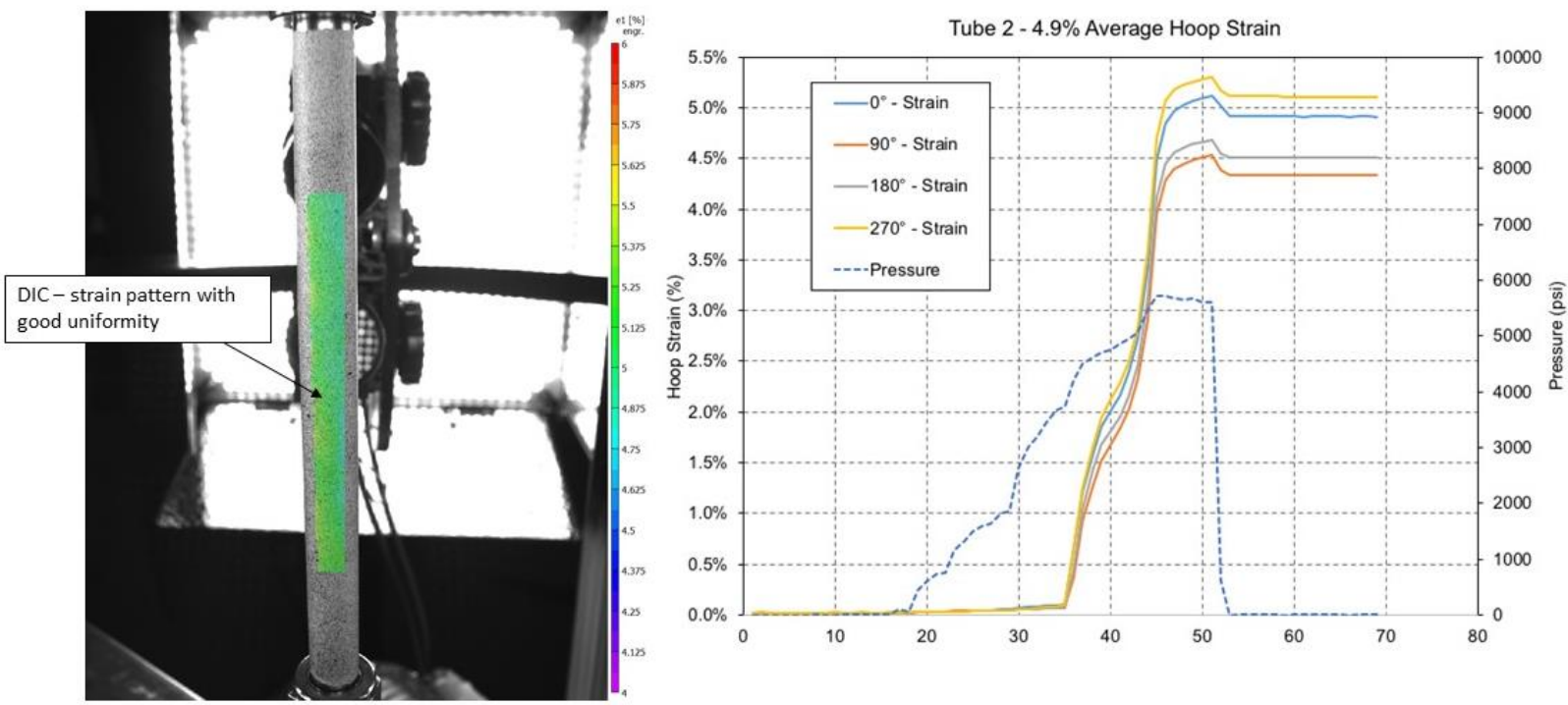

Figure 10. Hoop strain evaluation station at PNNL. 


\subsection{Concurrent Irradiation Testing}

In addition to experimental test positions and purpose built test capsules, TREAT also offers simplified access to its coolant channels for the testing of small diameter sensors or materials. At the corners of the square cross section fuel blocks are $15 \mathrm{~mm}$ square coolant channels, through which air is circulated [19]. Specially designed instrument test rods have been developed to allow installation of various sensors into these channels. The tubes are 0.25 inch outer diameter and 0.18 inch inner diameter. The tubes may be sealed on the end or left open, to allow a sensor too large to fit into the tube to hang below. The closed ended tube is 88 inches long. The instrument rod can be fitted with a standard Conax or Swagelok fitting at the top which is used to anchor the sensor or signal cable. To date, legacy SPNDs (used previously in TREAT) and optical fibers have been installed and tested. The instrument rods may be useful for rapid screening of materials and acoustic coupling strategies. Figure 11 shows the reactor top installation of instrument test rods into cooling channels in the TREAT reactor. A concurrent testing campaign planned for May, 2019 is being targeted for irradiation of piezoelectric transducers in an effort to quantify the effects of transient radiation and thermal effects on the transduction materials.

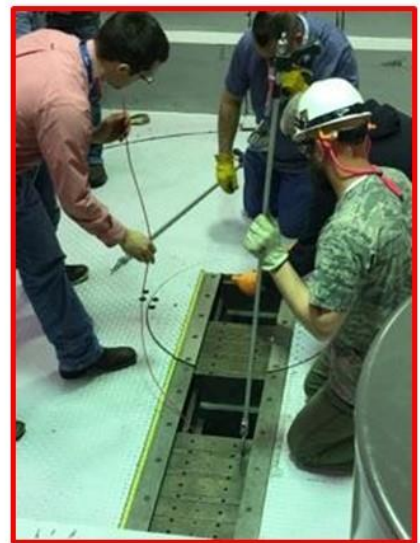

Experimenters lowering instrument rods into reactor with shield blocks removed

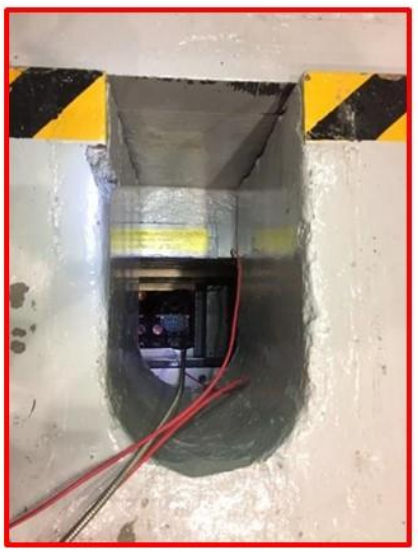

Instrument rods installed in reactor with shield blocks in place

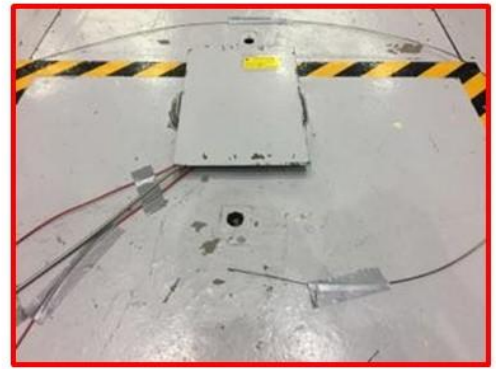

Reactor top experiment access

Figure 11. Installation of instrument test rods in TREAT cooling channels.

\subsubsection{Sensor Design for Concurrent Testing}

Figure 12 shows a current design for an ultrasonic transducer to be tested in the TREAT reactor coolant channels during concurrent testing. The transducer will be connected to monitoring equipment and actively interrogated during one or more transients in order to discern the effects on the piezoelectric element from the radiation and thermal environment. 


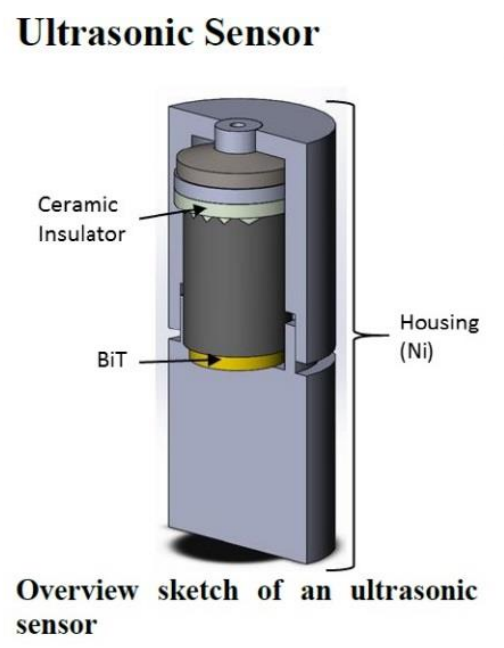

\begin{tabular}{|c|c|c|}
\hline $\begin{array}{l}\text { Ti-Holder } \\
\text { Description }\end{array}$ & Geometry & $\begin{array}{l}\text { Maximum In-Core } \\
\text { Mass/Sensor }\end{array}$ \\
\hline $\begin{array}{l}\text { Reference: } \\
\text { DWG-621267 } \\
\text { Modification: } \\
\text { Item } 11 \text { shortened to } \\
53 \text { inches. }\end{array}$ & $\begin{array}{l}\text { Sensor housing } \\
\text { (Ni-200): } \\
0.5 \text { " OD 0.382" ID } \\
1.01 \text { "L } \\
\text { Internal (Kovar): } \\
0.315 " \text { OD 0.375" L } \\
\text { (Bismuth-titanate): } \\
0.25 " \text { OD 0.039" L } \\
\text { (Inconel): } \\
0.354 " \text { OD } 0.063 " \text { ID } \\
0.03 " \mathrm{~L} \\
\text { Ceramic (Alumina): } \\
0.315 " \text { OD } 0.066 " \mathrm{~L}\end{array}$ & $\begin{array}{l}\text { Ni-200: } 24.9 \mathrm{~g} \\
\text { Kovar: } 3.1 \mathrm{~g} \\
\text { Inconel } 718: 0.4 \mathrm{~g} \\
\text { Bi4Ti3O12: } 0.1 \mathrm{~g} \\
\text { Ceramic: } 0.2 \mathrm{~g}\end{array}$ \\
\hline
\end{tabular}

Figure 12. Simplified sensor design for concurrent testing.

Within the reactor shielding, the sensor will be connected electrically to ex-core electronics via mineral insulated metal sheathed coaxial cabling (1-1.6 mm in OD) which will transition to standard coaxial cable outside the biological shielding. If needed, a pre-amplifier may be located inside the junction box at the top of the reactor floor. The cabling will then be routed to electronics located within the experimenters' room (Figure 13). 


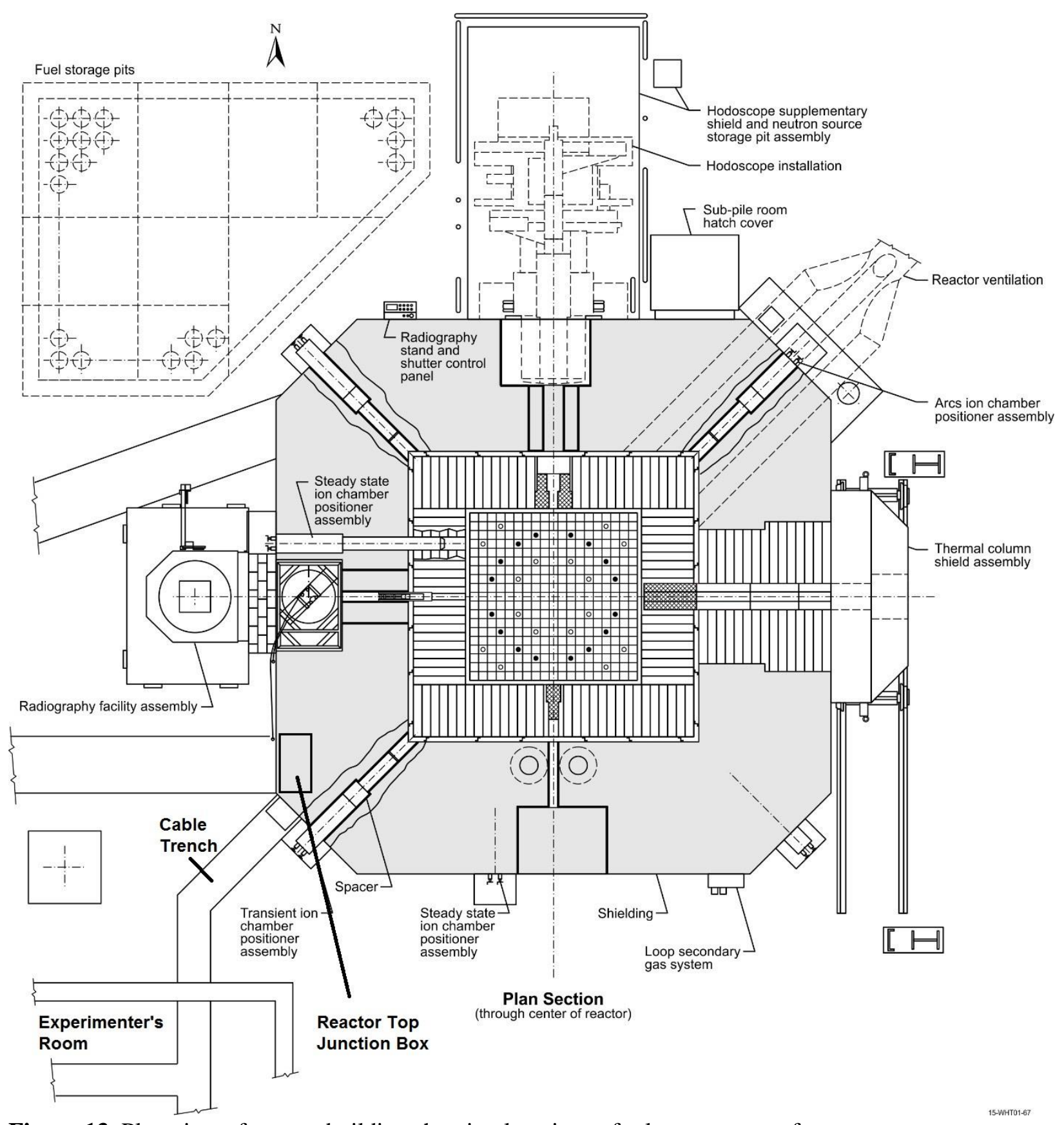

Figure 13. Plan view of reactor building showing locations of relevant ex-core features.

\subsection{Testing to Date}

Initial testing has been performed at PNNL at a benchtop scale. Several sensor concepts have been tested for measuring fuel pin diameter, length, and cladding thickness. These bench scale tests utilized standard transducers, not specially designed for use in TREAT irradiations, for testing different methods for measuring each parameter. Figure 14. Fuel pin diameter measurement testing. shows results for two methods tested for measuring fuel pin diameter changes. The first, a pulse-echo, two transducer technique, was water coupled with a standoff between tube and transducers. The second, a pulse-echo, shear wave technique, required coupling the transducer face to the tube surface. The use of an EMAT in 
place of the piezoelectric transducer could eliminate the need for direct coupling, but an EMAT still requires close proximity between the EMAT probe and the tube surface. Improved fixtures are expected to markedly improve measurement accuracy/consistency.
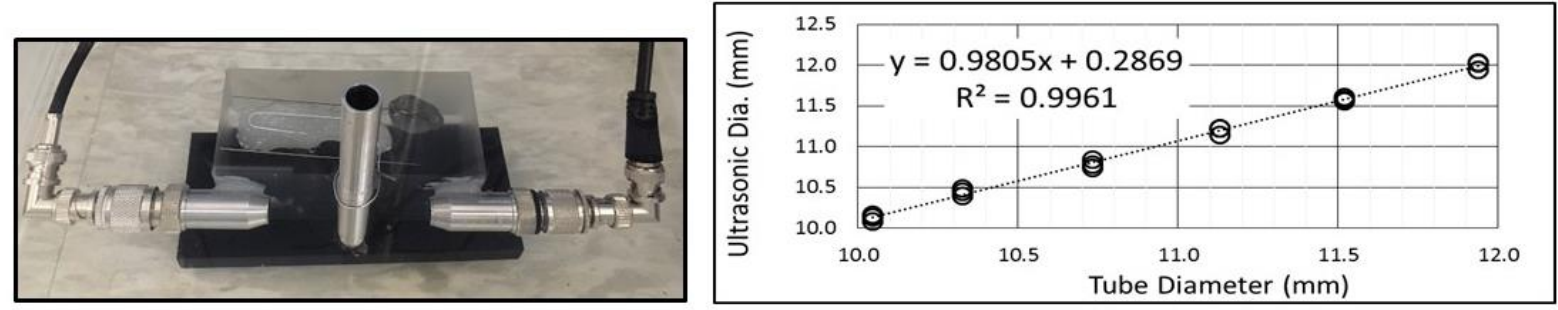

a) Pulse-Echo, Two Transducer Technique
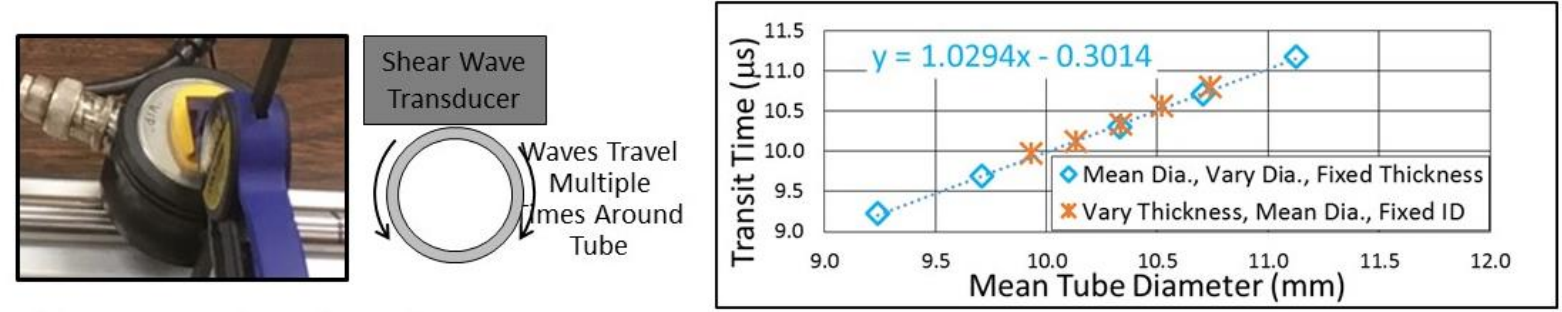

b) SH-Wave Pulse-Echo Technique

Figure 14. Fuel pin diameter measurement testing.

Figure 15. Fuel pin length measurement testing. shows results of testing two methods for measuring length changes of fuel pins. The first method uses pulse-echo, plate wave arrival time, which was found to be proportional to tube length. The second method was a resonance technique using selected resonance frequencies, which are inversely related to tube length. For both of these methods, it is required that the transducers be in contact with the tube end. Both may be integrated into the tube end cap or fuel pin hanger. 

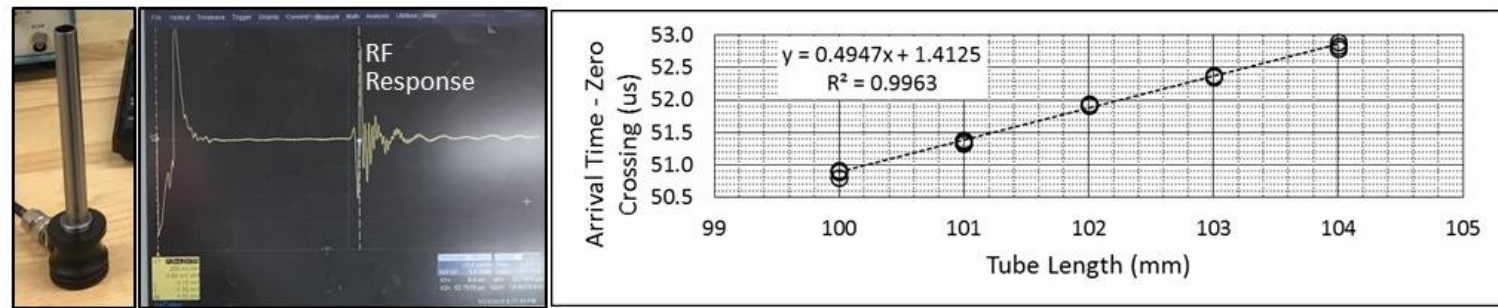

a) Pulse-Echo
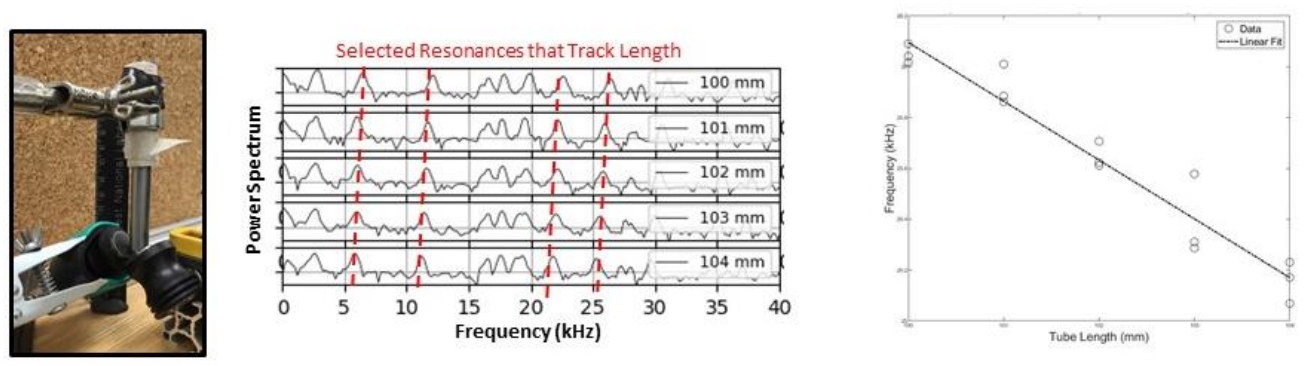

b) Resonance

Figure 15. Fuel pin length measurement testing.

Figure 16 shows results of testing a method to measure cladding thickness. Interference between outer and inner tube wall reflections creates spectral minima inversely related to thickness. The transducer and setup is similar to the pulse-echo, two transducer technique for diameter measurement. The two measurements; therefore, should be able to be done simultaneously but may require water coupling for sufficient signal amplitude.

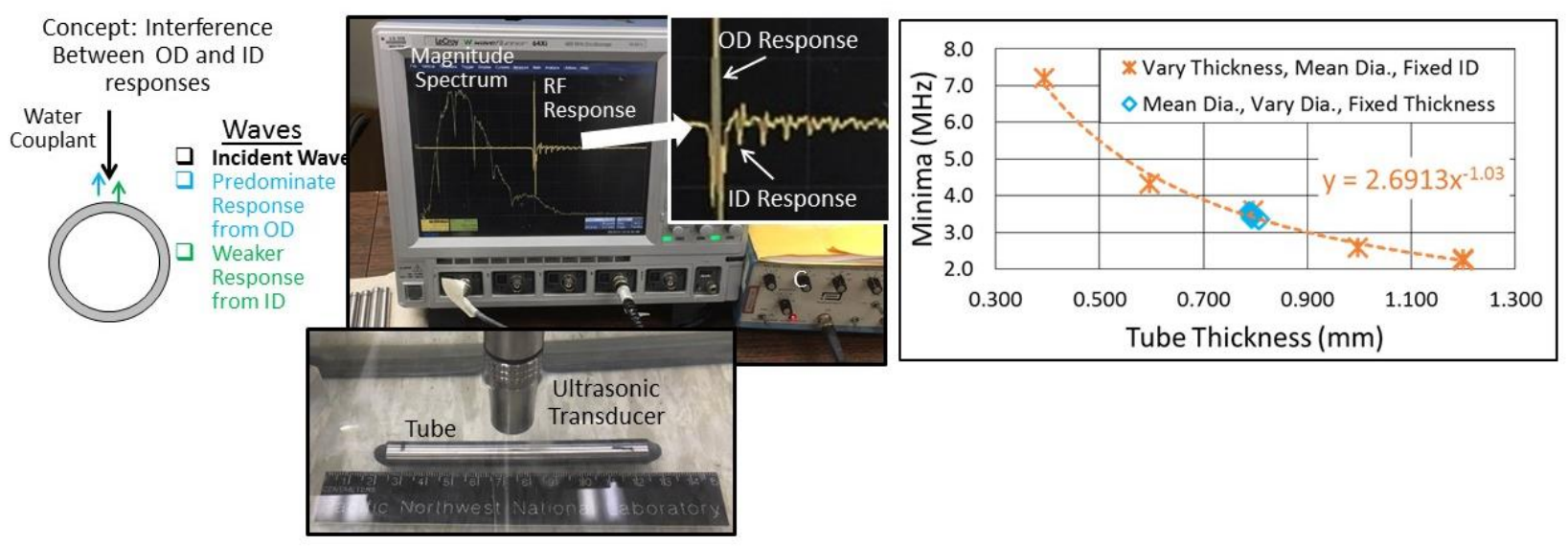

Figure 16. Fuel cladding thickness measurement testing.

\section{Integration Planning}

A significant amount of development work has already been done by the TREAT experiment program toward integrating large numbers of sensors into experimental capsules such as SETH. As such, existing designs and infrastructure will be used where available. Minor changes to hanger structure designs may be needed to accommodate the ultrasonic deformation sensor in an internally installed application. 


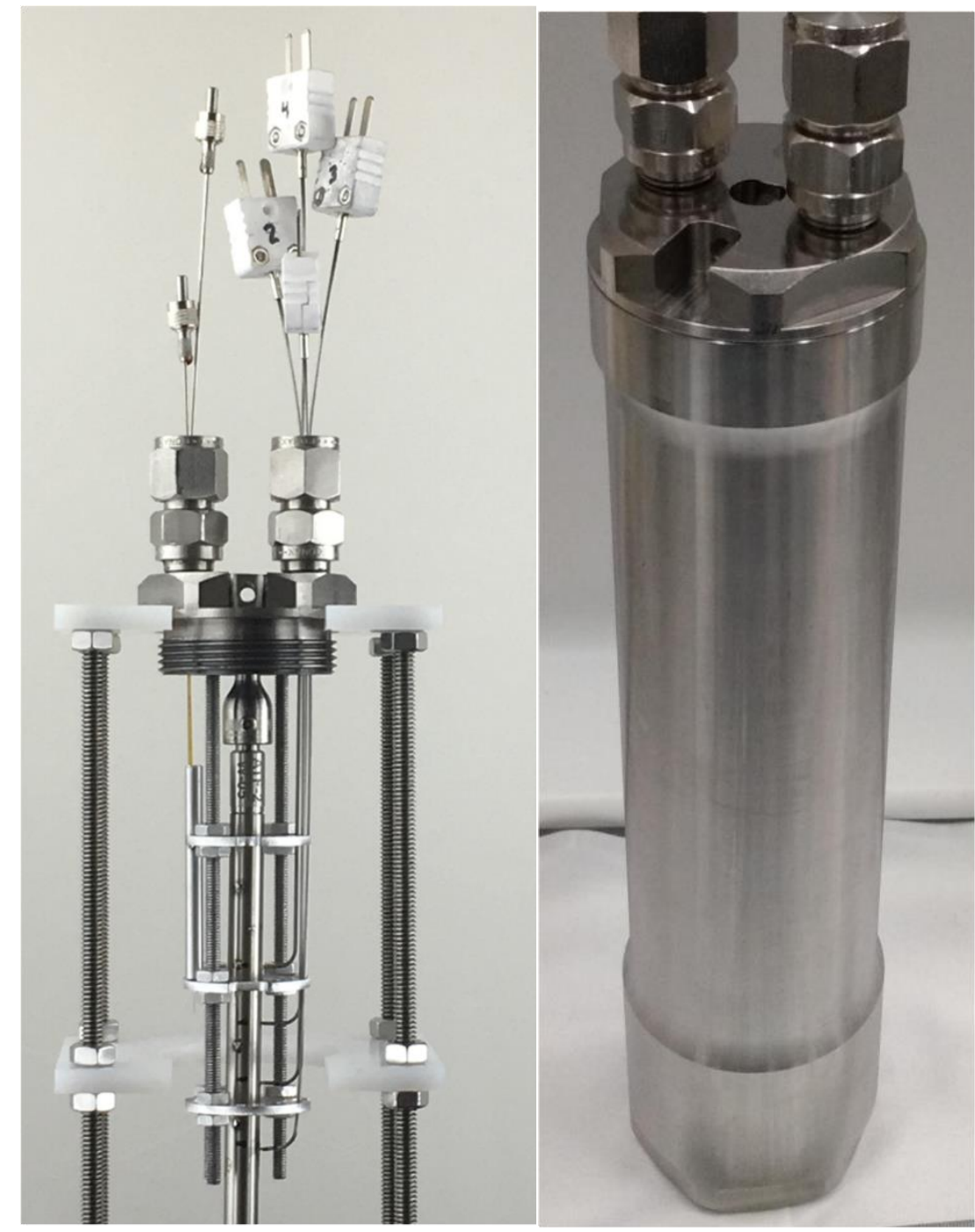

Figure 17. SETH capsule cap showing thermocouples and optical pyrometers installed on hanger structure.

For mockup and concurrent testing a suite of standard ultrasonic testing equipment will be used, including pulser/receivers, high speed digitizers, amplifiers, and oscilloscopes. Investigation of a standalone system is ongoing in the hope that a small, user friendly DAQ system can be deployed during future irradiation campaigns.

\section{Summary}

This report is meant as an update on progress related to mockup testing of prototypic ultrasonic deformation sensors and planning for integration of these sensors into TREAT experiments. Neither of these tasks are considered complete, and both will likely be ongoing throughout the duration of this project. Significant progress was made in terms of setting up mockup testing facilities with some benchtop evaluations performed. Integration planning is less developed, with many unknowns still present with respect to the final design of the sensor. 


\section{References}

1. C. Jensen, et. al., "FY17 Report for Instrumentation Development for the Transient Testing Program,” INL/EXT-17-43444, Sept., 2017.

2. Colby Jensen, "Experiment Instrumentation for Transient Testing," Advanced Sensors and Instrumentation 2016 NE I\&C Review, Oct. 12-13, 2016

3. C. Jensen, "Transient testing instrumentation needs," Presented at the 2016 DOE-NE ASI Program Review, October 2016.

4. Daw J, A Crawford, R Skifton, LA Hone, P Ramuhalli, RE Jacob, AM Casella and RO Montgomery. 2018. Design Requirements for Ultrasonic Deformation Sensor for TREAT Experiments. INL/EXT-18- 45209, PNNL-27635, Rev. 0. Idaho Falls, Idaho:Idaho National Laboratory

5. Ramuhalli P, MS Good, RE Jacob and J Daw. 2018c. Preliminary Assessment of Sensor Materials for TREAT Ultrasonic Dimension Sensor. PNNL-27727 Rev. 0. Richland, Washington: Pacific Northwest National Laboratory.

6. D. Fourmentel, J. F. Villard, et al, "Acoustic sensor for in-pile fuel rod fission gas release measurement," in First Int'l. Conf. on ANIMMA, 2009, pp. 1-5.

7. K. K. Phani, D. Sanyal, and A. K. Sengupta, "Estimation of elastic properties of nuclear fuel material using longitudinal ultrasonic velocity - A new approach," J. Nucl. Mater., vol. 366, pp. $129-136,6 / 30 / 2007$.

8. J. Daw, J. Rempe, et al., NEET In-Pile Ultrasonic Sensor Enablement-Final Report, Technical Report, PNNL-23746 (INL/EXT-14-32505), 2014.

9. R. Jacobs, P. Ramuhalli, and A. Casella, "Characterization of microstructural differences in irradiated nuclear fuel using ultrasonic NDE," IEEE Trans. UFFC (In preparation).

10. D. Ensminger and L. J. Bond, Ultrasonics: Fundamentals, Technologies, and Applications, 3rd ed.: CRC Press, 2012.

11. P. Ramuhalli, R. V. Harris, et al., "In-situ Characterization of Cast Stainless Steel (CASS) Microstructures," ed. Berlin, Germany, 2010.

12. M. R. Larche et al, "Progress in the development and demonstration of a 2D-matrix phased array ultrasonic probe for under-sodium viewing," AIP Conf. Proc., Vol. 1706, Issue 1, 2016.

13. D. R. Weier, and A. F. Pardini, Evaluation of UT Wall Thickness Measurements and Measurement Methodology, Technical Reprot, Pacific Northwest National Laboratory, PNNL16828, Oct 2007.

14. L. C. Lynnworth, Ultrasonic Measurements for Process Control: Theory, Techniques, Applications: Elsevier Science, 2013.

15. S. R. Doctor, "Nuclear Power Plant NDE Challenges - Past, Present, and Future," presented at the Review of Progress in Quantitative Nondestructive Evaluation, Portland, Oregon, 2007.

16. D. Baron, D. Laux, and G. Despaux, "Mechanical characterisation of irradiated fuel materials with local ultrasonic methods," in Pellet-clad Interaction in Water Reactor Fuels, 2004.

17. Prowant M, G Dib, H Qiao, M Good, M Larche, S Sexton and P Ramuhalli. 2017. "Preliminary Design of High Temperature Ultrasonic Transducers for Liquid Sodium Environments." In Review of Progress in Quantitative Nondestructive Evaluation, Provo, UT.

18. "FUTURE Transient Testing of Advanced Fuels," Summary of the May 4-5, 2009 Transient Testing Workshop Held at Idaho National Laboratory, 2009.

19. “TREAT Baseline Description Document," ANL/RAS 72-23, Aug., 1972.

20. N. Woolstenhulme, C. Baker, J. Bess, D. Chapman, C. Jensen, C. Hill, D. Wachs, S. Wilson, "Status Report for NEET In-Pile Sensor Irradiation Capabilities at TREAT," INL/EXT-17-43274, Sept., 2017

21. N.E. Woolstenhulme, "Update on TREAT Restart and Experimental Design Preparations," OSU IRP Meeting November 2017, Corvallis, WA. 
22. Dan Wachs, "Status of Transient Testing Capabilities in the United States," GAIN Workshop on Fuel Safety Research, Idaho Falls, ID, May1-5, 2017. 